\title{
A Conceptual Model for Success in Implementing Knowledge Management: A Case Study in Tehran Municipality
}

\author{
Manoucher Ansari ${ }^{1}$, Hossein Rahmany Youshanlouei ${ }^{2 *}$, Mohammad Mirkazemi Mood ${ }^{3}$ \\ ${ }^{1}$ Faculty Management, University of Tehran Chamran Highway, Tehran, Iran; ${ }^{2}$ Young Research Club, Salmas Branch, Islamic Azad \\ University, Salmas, Iran; ${ }^{3}$ Management Faculty, University of Tehran, Tehran, Iran. \\ Email: $\left\{{ }^{*}\right.$ Rahmani82,md.mirkazemi\}@gmail.com,mansari@ut.ac.ir
}

Received January $20^{\text {th }}, 2012$; revised February $24^{\text {th }}, 2012$; accepted March $1^{\text {st }}, 2012$

\begin{abstract}
In this "information and knowledge" age, instead of traditional financial assets and even large markets, knowledge capital has been the competitive edge for major corporations. This has lead to a new concept called "knowledge management". Indeed, the identification of knowledge in business sectors as a competitive advantage and strategic resource intensifies the necessity of implementation of knowledge management (KM) in organizations. Knowledge management is the process of identifying, selecting, organizing, and transferring important information and skills, which exists as disorganized form in the organization. However, there are several stories of failed implementation of knowledge management in organizations. In order to succeed in implementing knowledge management, identification of the success factors for knowledge management is of great importance. The current research has therefore presented a conceptual model for implementing knowledge management successfully in Tehran municipality. This study has first identified effective variables on success of knowledge management; then has evaluated its significance and developed a conceptual model for the critical factors on successful knowledge management in the organization under study. According to the conceptual model offered by this research, these critical success factors are dimensions of organizational culture, strategy and leadership, organizational structure, information technology infrastructure and human resources.
\end{abstract}

Keywords: Knowledge Management; Critical Success Factors; Tehran Municipality

\section{Introduction}

The current world is experiencing an era in which knowledge is a basic commodity, knowledge streams have been highlighted as the most important factor of economy [1]. And knowledge has been transformed into a competitive advantage. In such a situation, those organizations can hope to survive which rely on their knowledge itself rather than their physical assets [2]. Therefore, by accepting the knowledge as a strategic resource for organizations and its significance on the organization's capability and stability within the competitive environment, there has been appeared an urgent need to create techniques for creating, sharing, and employing knowledge in the organizations. In order to use this valuable asset, the organizations are required to manage their knowledge properly. Knowledge management is a process which helps the organizations to identify, choose, organize, distribute and share significant information and skills, as a part of their context, and is usually available in unstruc-

*Corresponding author. unstructured form [3]. Applying the knowledge management based on their knowledge and intellectual capital will enable the organization to produce wealth or to create value from intellectual and knowledge-based assets [4]. However, lack of sound mechanisms to analyze and implement knowledge management as well as the essential prerequisites, has made this kind of investment seem as an extra expenditure in managers' point of view [5]. In order to prevent this issue, organizations must first launch to identify critical success factors for implementing knowledge management and then, provide appropriate base to implement it through investment on the identified factors; since knowledge management is a set of factors by effective and coordinated interaction of which, it will be accomplished successfully. Critical success factors are a limited number of activities which would lead to competitive success [6]. These factors can impose significant effect on success of competitive position for the organization if managed correctly [7]. They will also improve the chance to execute projects [8]. Critical success factors have a key role in successful implementation of 
knowledge management meanwhile providing proper infrastructure for them can lead to successful knowledge management [9]. This paper aims at suggesting a conceptual model for successful knowledge management in order to make solidarity among the results from previous studies which had commonly analyzed the effect and relation of effective elements of critical success factors in implementing knowledge management qualitatively and intellectually. It will also try to offer a localized model for a semi-governmental organization in Iran as a case study. The following sections of this paper deals with identifying literature review of critical success factors in implementing knowledge management in previous studies and providing methodology to collect and analyze data. At the end, having compared results of the current research with that of the previous ones, practical conclusions will be made for managers to implement knowledge management successfully within organizations.

\section{Literature Review}

Knowledge management was at first just a process to adopt a systematic approach to gain, structure, manage and distribute knowledge throughout an organization in order to implement tasks quickly, reuse procedures and reduce unnecessary repeats[4]. However, Davenport believes that knowledge management is trying to explore the properties hidden in individuals' mind and transfer this hidden "treasure" to organizational assets which can be accessible and usable extensively by people who are responsible for organizational decision making [10]. In Jung's point of view, knowledge management is an integrated systematic approach to identify, manage and share all informational properties of the organization including database, documents, policies and procedures. Benefits and necessities of using knowledge management have been frequently emphasized in the literature such that Drucker(1993) [11] argues that secret of success for organizations of $21^{\text {st }}$ century is concealed in adequate implementation of knowledge management which includes reusing the existing knowledge and prevention from repeated expenditures to solve the same problems. Knowledge management reduces the time duration from problem declaration to problem resolution. It also leads to reinforce strategy of innovative organization, maximize internal performance, coordination, service to customers and general profit, creation of value and creativity $[12,13]$.

One of the most considerable parts of knowledge management literature is the critical success factors of knowledge management. Various studies have been launched on these factors and their obtained results have disparities regarding the differences between industry and environment of them. Critical success factors are used to identify and prioritize business requirements and techni- cal systems [14]. These are fixed samples which contribute to improve the process and will have significant effects if considered at adequate steps [15]. Knowledge management is not a one day activity; it needs a harmonic plan composed of a limited set of regions (critical factors) to result a successful performance. These regions are called critical success factors in knowledge management [16]. Skyrme and Amidon (1997) [17] have distinguished seven key factors in implementing the knowledge management namely: robust commitment to the business, architecture and vision, leadership, culture, continuous learning, technological infrastructure and organizational knowledge processes. Davenport and his colleagues (1998) [10] accomplished an exploratory study on 31 projects of knowledge management through 24 companies. The main goal of this extensive research was to determine the key factors related to implementation of knowledge management. They identified 7 key success factors within 18 successful projects which were: value of industry, common language and goal, flexible and standard structure of knowledge, multiple channels to transmit knowledge, culture, organizational and technical infrastructure, motivational actions and support from senior management. One other investigation has been done by Holsapple and Joshi (2000) [18] to identify key success factors. First, they have extracted a set of factors from the literature and then, they have applied Delphy technique to evaluate the identified factors within experts' society of knowledge management. They have introduced three major classes of factors (managerial, resources and environmental) and the key factors lies in one of them. Managerial factors have four key factors namely coordination; control, leadership and measurements; factors related to resources of knowledge, individuals, financial and nonfinancial resources; and finally, environmental factors such as competition, markets, time compulsion, economic and governmental atmosphere. Chourides et al. (2003) [19] have identified varied critical factors to successfully implement knowledge management in five functional scopes of the organization: strategy, management of human resources, information technology, quality and marketing. Although, their product was rather a list of tasks to-be-done for example enhance delivery time of the product to market and increase the speed of organization in responding to customer needs. Yu et al. (2004) [20] in an article titled "relation between drivers of organizational KM and performance of KM: an exploratory study", studied the relation between organizational culture and success of knowledge management within 66 Korean companies in an attempt to explore the relation among drivers of knowledge management and performance of organizational knowledge management. They have discovered that knowledge management driver including learning culture, ef- 
fort to share knowledge, quality of knowledge management system, compensations and activity of knowledge management team will considerably affect knowledge management performance. Eventually, they have categorized nine enablers of knowledge management in three classes of organizational characteristics, information technology and managerial support. Wong (2005) [21] introduces eleven success factors after studying several literatures and identifies their limitations: support of management and leadership, culture, information technology, strategy and goal, evaluation, organizational infrastructure, activities and processes, motivation, resources, education and training, management of human resources. Chong \& Choi (2005) [22] have noticed eleven key factors in implementing knowledge management successfully which are: training employees, involvement of employees, teamwork, delegation, leadership and commitment of senior management, removal of organizational limitations, IT infrastructure, knowledge-based performance criteria, knowledge-friendly culture, comparative study, and knowledge structure. Wong and Aspinwall (2005) [23] have examined eleven success factors in their research and have sorted them in terms of importance for medium and small organizations. Their factors were: leadership and support management, culture, strategy and goal, resources, processes and activities, education and training, management of human resources, information technology, motivational reinforcements, organizational infrastructure and evaluation. Hung et al. (2005) [24] have also chosen commitment and leadership of senior management, involvement of the employees, reliable teamwork, supporting the employees, infrastructure of informational systems and performance evaluation as the factors of successful knowledge management. Akhavan et al. (2006) [25] in their article named "Critical success factors of knowledge management systems: A multiple case study" have proposed a set of critical success factors in addition to a conceptual framework as the map for success in application of knowledge management systems using approach of grounded theory and data from some successful companies in implementing knowledge management systems. Yeh et al. (2006) [26] presented a paper on "Enablers of knowledge management: A case study" in which they aim to analyze fundamental role of the enablers for execution of knowledge management inside the organization. They argue that these enablers can develop knowledge; stimulate, share and keep knowledge creation within the organization; and enhance or influence activities of knowledge management. They introduce organizational culture, individuals, information technology, and strategy and leadership as enablers of knowledge management by investigating on the previous literature. They claim that support from senior managers of the organization is the most significant part for strat- egy and leadership. Anantatmula and Kanungo (2007) [27], in their study named "modeling the enablers to implement knowledge management successfully", conclude from the literature that there are 13 factors which play role in successful implementation of knowledge management. Then, they determine underlying relations between these factors and develop strategies for successful implementation of knowledge management.

After extensive study on the literature in order to identify critical success factors in of Knowledge Management (KM) according to the previous investigations from 1997 to 2010 within the organizations, 5 main factors were identified for successful implementation of KM. Table 1 has summarized these 5 factors along with the name of authors who have initially noticed them.

Next section deals with analyzing individually the most important critical success factors which was mentioned in Table 1.

\section{Critical Success Factors in Successful Implementation of Knowledge Management}

\subsection{Culture}

Organizational culture is comprised of common values, believes and norms for members of an organization which correlated them to each other [28]. Organizational culture determines how affairs are done in the organization for its employees. Indeed, culture is the same understanding of organization which is observed within all members and is indicative of common and constant specifications which distinguish the organization from other organizations. In other words, Organizational culture specifies social identity studies of any organization [29]. Organizational culture has emerged as a key factor for organizational changes and modifications [29]. Based on Peter and Waterman, human elements which exist in the culture are regarded as effective key determinants on business performance and change management. Davenport and Pursak (2000) [2] notice organizational culture as the fundamental index to evaluate success of knowledge management within organizations; such that successful

Table 1. Critical success factors in the literature.

\begin{tabular}{ll}
\hline Critical Success Factors & \multicolumn{1}{c}{ Authors } \\
\hline Culture & {$[10] ;[40] ;[26] ;[17] ;[24] ;[44] ;$} \\
Structure & {$[35] ;[19]$} \\
Strategy and Leadership & {$[10] ;[40] ;[24]$} \\
Human Resource & {$[26] ;[17] ;[18] ;[24] ;[44] ;[35]$,} \\
Information Technology & {$[40] ;[26] ;[17] ;[19] ;[24] ;[10] ;[35]$} \\
\hline
\end{tabular}


knowledge management in the organization depends on its value in the organizational culture [2]. Trust, participation, encouragements, participation leadership and forces to develop organizational goals are considered in relation with organizational culture [30]. Organizational culture is formed and supported through inter-related components of strategy, individuals, process and structures [31]. Many published works and experts in this field believe that the organizational culture has major effect on knowledge management or sharing. The same principles which are used for the culture can be also applied for knowledge management, since the organization can have a knowledge-based culture. Such a knowledge-based culture may challenge individuals throughout the organization to distribute the knowledge [2]. Many researchers have recognized organizational culture as one of the necessary factors to implement knowledge within an organization [10, 32,33]. Achieving the knowledge culture requires managerial attention to three aspects: preparation of organization, managing knowledge properties, and application of knowledge for competitive advantage [34]. If the organization tends to distribute knowledge in essence, then enabling the distribution will be much easier. When the organization develops a culture to store knowledge, negative consequences of its distribution must be kept away from the organization. People would like to share their knowledge and they want to be aware of knowledge ability of others. Therefore, the required tools and environment must be provided for those who choose to distribute their knowledge in this way, while some procedures must be created in order to support knowledge creation and distribution attempts [35]. As a result, managers of the organization should try to render knowledge management rules and procedures within the organization as cultural norms [32]. Table 2 has summarized criteria of cultural factor which have been mentioned in the literature.

\subsection{Structure}

Increased competition and fast rate of technologicalchanges, have necessitated better transfer of knowledge within task boundaries of organization [36].

The structure can be defined as a set of solutions in which people are categorized in different tasks. It also

Table 2. Organizational culture criteria.

\begin{tabular}{lll}
\hline Factor & \multicolumn{1}{c}{ Criteria } & \multicolumn{1}{c}{ Authors } \\
\hline & Trust & {$[55] ;[26] ;[40],[10] ;[38]$} \\
& Collaboration & {$[55] ;[56] ;[40]$} \\
& Open climate & {$[10] ;[38] ;[30] ;[42]$} \\
Culture & Learning from mistakes & {$[32] ;[42]$} \\
& Creativity and innovation & {$[26] ;[57]$} \\
& Knowledge sharing & {$[5] ;[58] ;[59] ;[57]$} \\
\hline
\end{tabular}

determines how to coordinate among different tasks [37, 38]. The organizational structure, determines a method in which the decision-making process is occurred as well as the responsibilities for materials, resources and human processes. Furthermore, such a structure must be flexible enough to increase knowledge distribution and cooperation from traditional borders of the organization towards knowledge creative borders [36]. On the other hand, formality and non-centralization factors have significant influence on coordination and cooperation inside the company in addition to knowledge creation and distribution $[38,39,40]$. A concentrated structure will prevent communications between units and profusion of idea distribution; it will also cause deviation and discontinuance in ideas due to its time-consuming communication channels [40]. In order to ensure proper distribution of the knowledge, communicational channels are required to be made as smooth as possible [3]. Organizational structure has been particularly emphasized for successful implementation of knowledge management. According to Ostroff, horizontal organizations are more convenient for information era. Horizontal organizations let much flexibility in relation to the environment with prompt and competitive changes of business [41]. Besides, successful implementation of knowledge management depends on flexible structure and elimination of conventional control systems [30]. Fault tolerance of management is dependent on policies to create a plain organizational structure which permits important decisions in all levels [42]. Table 3 has summarized criteria of structure factor which were previously discussed in the literature.

\subsection{Human Resource}

Individuals inside the organization are denoted as social enablers of knowledge management or main factors of knowledge creation and distribution [39]. Employees build any organization so they are crucial for its success. Individuals, who are the end users of system and technology, must have proper skill and sufficiency, task expertise, attitude, positive thought and sound culture for acceptance. They are significant since any change or newly introduced technology affects labor within organization [41]. McDermott (1999) [43] insists on the importance of individuals in the process of knowledge sharing which must be triggered for involvement in an

Table 3. Organizational structure criteria.

\begin{tabular}{lll}
\hline Factor & Criteria & Authors \\
\hline & Centralization & {$[40] ;[38] ;[30] ;[41] ;[36]$} \\
Structure & Formalization & {$[40] ;[59]$} \\
& Communicational channels & {$[10],[52],[35]$} \\
\hline
\end{tabular}


activity. This process needs additional time and may have risk of losing power and position. Therefore, it is necessary to evaluate organizational culture and personal preparedness in accepting innovative and new technologies [41]. Generally speaking, Individuals are regarded as personal contributors who have skills and knowledge roles, motivation and self-reaction, support, learning/ social networks, dialogues, coordination and innovation [44]. They create knowledge within the organization and a significant part of the organizational knowledge is saved in their minds, thus small mutation in their task positions can impose a fundamental effect on its total performance [45]. Considerable effects on this concept have caused a movement in the market, from severely worker-based industries toward knowledge-based industries, with increased educational opportunities $[46,47]$. Although the concept of knowledge workers is made for long time, few organizations have rather defined this role [10]. (Ruggles (1998) [48] explains that individuals should have a 50\% concentration in time and budget of knowledge management. Individuals within organizations must be usually consistent with organizational culture. Change in the culture of organization requires change in the attitudes and demolition of the old traditions. Therefore, human affairs must be considered as main factor inside the organizational changes of knowledge management. These considerations in the organization have put forward the concept of knowledge workers [45]. Furthermore, in order to execute knowledge management efficiently, human resources must contribute to form team of knowledge management, undertake plan of knowledge management, normalize rules of knowledge management, execute activities of knowledge management and enhance plan of knowledge management [32] Table 4 has summarized criteria of human resources factor which have been noticed in the literature.

\subsection{Information Technology}

Information technology (IT) is one of the effective factors on knowledge management. This factor covers all aspects of communications including software, hardware and their accessibility. This viewpoint is presented according to the technical ability of IT in receiving data, information and knowledge which has prominence in comparison with human capacity to attract and analyze data through a concentrated technique [49]. In spite of the importance of features related to technological per-

Table 4. Human resource criteria.

\begin{tabular}{lll}
\hline Factor & Criteria & Authors \\
\hline \multirow{2}{*}{ Human resource } & Employees participation & {$[44] ;[55]$} \\
& Employees training & {$[44]$} \\
\hline
\end{tabular}

formance, they cannot run the requested job and will be useless when there is not sufficient infrastructure technology [41]. Knowledge management activities are not practical software, but rather an infrastructure to distribute information and communicate just with one part of knowledge management activities [35]. Ruggles (1998) [48] argues that technology must receive some $25 \%$ of total time and budget. Technology can be considered both as a key helper and enabler in knowledge management [10]. Role of IT for knowledge management is to backup knowledge repositories, increase access and transmission of knowledge and facilities of knowledge environment. It can also provide personal, group and organizational interactions [5]. Besides, IT can contribute to knowledge creation processes in scientific environments as the enabler tool of knowledge [50]. Intimacy of IT and $\mathrm{KM}$ is significant since both of them will help to promote structured knowledge [51]. IT must serve individuals although it enables knowledge management. As a result, it must be built simple and user-friendly such that employees could use it without aid of IT experts [35]. IT is able to search quickly, access and recover information, backup cooperatively and communicate within members of the organization. In fact, it is able to play various roles for backing up processes of knowledge management. The goal of many organizations is to use advancements in IT in order to implement knowledge management properly [51]. Table 5 has summarized criteria of IT element which have been mentioned previously.

\subsection{Leadership and Strategy}

Activities of organizational knowledge management are exposed to numerous challenges in its initial steps. To achieve their targets in the future, organizations need to direct their knowledge management activities toward real efforts based on a clear strategy or plan. Therefore, one basic element to succeed, is to form an official strategy of knowledge management throughout the organization as well as plans to learn from the best practices and develop modern knowledge management [45]. Another issue in the field of strategy is that knowledge management must be aligned with the organizational strategy[1]. One type of strategies to implement KM is using benchmarking. The organization can adopt the follow-

Table 5. Information technology criteria.

\begin{tabular}{lll}
\hline Factor & Criteria & Authors \\
\hline & $\begin{array}{l}\text { Access to network infrastructure } \\
\text { and hardware }\end{array}$ & {$[60] ;[61] ;[56]$} \\
Information & Access to applied software & {$[60] ;[61] ;[56]$} \\
technology & Flexibility & {$[60] ;[61] ;[57]$} \\
& IT employees & {$[60] ;[61] ;[40] ;[26]$} \\
\hline
\end{tabular}


ings to do so:

- provide guidance to actualize a pattern-made system,

- encourage people for pattern-making from the best organizations in this field,

- establish internal pattern-making based on strategy coordination, budget and systems of human resources [22].

Additionally, role of the leader has been emphasized within the organization in implementing KM since it has the key role in succeed of KM activities in the organization [22,30,35]. Leaders execute business strategies for survival and success in current dynamic environments. They also determine the vision and adopt to align KM with business strategies to proceed value of KM throughout the company [52]. Leaders should support KM procedures and projects (Chong \& Choi, 2005) [22] and ensure sufficient allocation of resources in terms of time, labor and money for projects and operations [22,41]. The behavior which leaders try to promote among their customers has the most significant effect on the organization [35]. Furthermore, style of leadership and strategic role of him/her can improve the initial (basic) process and provide ideas for improvement and backup [30]. Commitment of leader is usually at the same level with senior management as they promote concepts and offer guides, instructions and supports [35]. A good example for role of leadership in successful implementation of KM is world bank in which supports of senior management of the organization has led to an infrastructure to promote and backup growth of practical communities of knowledge throughout the entire organization [35]. Table 6 demonstrates leadership and strategy criteria which have been previously discussed in the literature.

\section{Conceptual Model of Research}

The following will proceed to represent a conceptual model of research taking into account the provided issues in introducing the crucial factors of successful KM according to Figure 1. Hypotheses of research have been listed below regarding this model:

- Organizational culture affects application of KM within organizations.

- Organizational structure affects application of KM within organizations.

- Human resources affect application of KM within organizations.

Table 6. Strategy and leadership criteria.

\begin{tabular}{lll}
\hline Factor & Criteria & Authors \\
\hline \multirow{3}{*}{$\begin{array}{l}\text { Strategy and } \\
\text { leadership }\end{array}$} & Knowledge strategy & {$[26] ;[59] ;[1] ;[22]$} \\
& Reward policies & {$[60] ;[26] ;[59]$} \\
& Supporting top management & {$[60] ;[61] ;[26] ;[5]$} \\
\hline
\end{tabular}

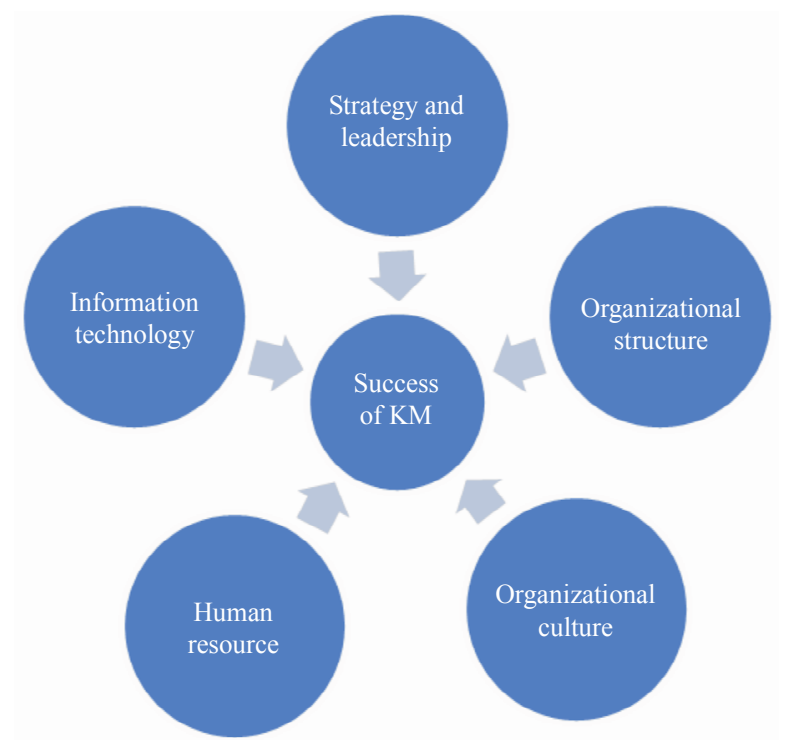

Figure 1. Research conceptual model.

- IT Infrastructure affects application of KM within organizations.

- Strategy and leadership affect application of KM within organizations.

\section{Research Methodology}

Since the aim of this research is to determine causal relations between variables of organizational culture, strategy and leadership, organizational structure, IT infrastructure and human resources, the research is practical in terms of its target and correlative-descriptive in terms of method of collecting information; it is specifically based on structural equations. In order to evaluate the relations between different variables within the recent decades, numerous techniques have been proposed. One of these techniques is the model of structural equations model or multi-variant analysis using latent variables. Model of structural equations is a comprehensive approach to examine hypotheses about relations between the observed variables and latent variables. By this approach, one can check credibility of theoretical models in special communities. Since majority of the existing variables are latent or hidden, necessity to use these models are being more pronounced every day. In the analysis model, organizational culture, strategy and leadership, organizational structure, IT infrastructure, human resources and success of knowledge management are exogenous variables.

Main tool to collect information was a questionnaire including 75 questions about successful KM in different aspects. Thereby, for the variables under study, 15, 12, 10,12 and 13 questions were considered for organizational culture, organizational structure, IT infrastructure, strategy and leadership and human resources, respec- 
tively, by 5-level Likert scale. Also, statistical sample of the research was 284 people of Tehran municipality employees. In order to evaluate the reliability, an initial sample of 30 questions was pre-tested. Then, using the results obtained from this questionnaire, coefficient of confidence was calculated $87 \%$ from technique of Cronbach's Alfa. This value was also measured for the questions of variables: organizational culture $(73 \%)$, organizational structure $(76 \%)$, IT infrastructure $(79 \%)$, strategy and leadership (74\%) and human resources (81\%). These figures indicate that the questionnaire has the required confidence or better to say reliability. In order to evaluate validity of the questions, factor validity was employed which is a form of structure credit and is obtained through factor analysis [53], Factor analysis is a statistical technique used extensively in humanism. In fact, application of factor analysis is necessary and essential where questionnaires and tests are used with latent variables [54]. Since all questions of the questionnaire used in evaluating the structure were based on previous studies, then revised by some professors and managers, and eventually the initial questionnaire has been edited and the final questionnaire has been codified based on their feedbacks and in order to decrease ambiguities, one can ensure of validity of its contents. Validity of the structure was also studied within the confirmatory factor analysis based on Lisrel software and its results are illustrated in Table 7.

\section{Research Findings}

Two-phase procedures have been employed for testing the model. First, the measurement model has been tested

Table 7. The first order CFA and EFA results for the KM success.

\begin{tabular}{|c|c|c|c|c|c|c|c|}
\hline \multirow[b]{2}{*}{ factor } & \multicolumn{2}{|c|}{ CFA loadings } & \multicolumn{5}{|c|}{ EFA loadings (after varimax rotation) } \\
\hline & Loading & $\mathrm{t}$-value & $\begin{array}{l}\text { Human } \\
\text { resource }\end{array}$ & $\begin{array}{l}\text { Organizational } \\
\text { structure }\end{array}$ & $\begin{array}{l}\text { Organizational } \\
\text { culture }\end{array}$ & IT & $\begin{array}{l}\text { Strategy and } \\
\text { leadership }\end{array}$ \\
\hline Centralization & 0.67 & 14.91 & 0.113 & 0.742 & 0.110 & 0.042 & 0.364 \\
\hline Formalization & 0.56 & 12.05 & -0.010 & 0.650 & 0.157 & 0.050 & 0.087 \\
\hline Communicational channels & 0.81 & 18.64 & 0.007 & 0.821 & 0.061 & 0.121 & 0.187 \\
\hline $\begin{array}{l}\text { Access to network infrastructure } \\
\text { and hardware }\end{array}$ & 0.74 & 18.33 & 0.069 & -0.005 & 0.136 & 0.81 & 0.144 \\
\hline Access to applied software & 0.85 & 22.24 & 0.038 & 0.021 & 0.005 & 0.87 & 0.056 \\
\hline Flexibility & 0.61 & 14.15 & 0.110 & 0.029 & 0.110 & 0.76 & 0.048 \\
\hline IT employees & 0.82 & 21.18 & -0.039 & -0.021 & 0.164 & 0.88 & 0.113 \\
\hline Knowledge strategy & 0.86 & 21.63 & 0.087 & -0.062 & 0.174 & 0.091 & 0.88 \\
\hline Supporting top management & 0.74 & 18.05 & 0.074 & -0.008 & 0.156 & 0.167 & 0.72 \\
\hline Employees participation & 0.64 & 6.38 & 0.70 & 0.003 & 0.076 & 0.107 & 0.084 \\
\hline Employees training & 0.51 & 6.04 & 0.61 & 0.122 & -0.012 & 0.184 & 0.069 \\
\hline Trust & 0.67 & 15.85 & -0.162 & 0.119 & 0.77 & 0.031 & -0.052 \\
\hline Collaboration & 0.80 & 20.19 & -0.062 & 0.218 & 0.73 & -0.015 & 0.030 \\
\hline Open climate & 0.69 & 16.71 & -0.018 & 0.114 & 0.74 & 0.054 & 0.059 \\
\hline Learning from mistakes & 0.71 & 17.34 & 0.013 & 0.106 & 0.69 & 0.004 & -0.023 \\
\hline Creativity and innovation & 0.66 & 15.48 & 0.222 & 0.196 & 0.64 & -0.032 & 0.134 \\
\hline Knowledge sharing & 0.59 & 13.48 & -0.062 & 0.245 & 0.62 & 0.110 & 0.103 \\
\hline $\begin{array}{l}\text { Goodness-of-fit statistics } \\
\chi^{2}=2800.14 \\
\text { df }=125 \\
\text { CFI }=0.99 \\
\text { NFI }=0.98 \\
\text { RFI }=0.98 \\
\text { TLI }=0.98 \\
\text { RMSEA }=0.066\end{array}$ & & & & & & & \\
\hline
\end{tabular}

NOTE: CFA = Confirmatory factor analysis; EFA = Exploratory factor analysis; CFI = Comparative Fit Index; NFI = Normed Fit Index; RFI = Relative Fit Index; TLI = Tucker-Lewis Index; RMSEA = Root mean square error of approximation. a. Total variance extracted by the four factors = 74\%; rotation method: oblimin with Kaiser normalization; average interfactor correlation $=0.51$; loadings $<0.30$ not shown. $b$. These are standardized loading estimates from CFA using the Amos software package. c. Based on one-tailed tests, t-values greater than 1.65 are significant at $\mathrm{p}<0.05$; $\mathrm{t}$-values greater than 2.33 are significant at $\mathrm{p}<0.01$. 
by confirmatory factor analysis and then, it was adopted to test the structural model. In order to determine the structural credibility and fit the pattern, confirmatory factor analysis was used while Structural Equations Modeling was utilized to fit the final model. Lisrel software was used to process the data.

Figure 2 (model of success evaluation in KM) provides the model obtained from confirmatory factor analysis. It demonstrates five success factors of KM namely organizational structure, IT infrastructure, strategy and leadership, human resources, and organizational culture. Organizations whose above factors are in good situation can get more success than those whose above factors are not in an acceptable situation. Thus, these five factors can be noticed as complements for successful implementation of KM within organizations.

For confirmation of the proposed model, it can be argued that RMSEA value was obtained as 0.057 which was less than 0.08, meanwhile, two indexes of GFI and AGI were also calculated to be 0.93 and 0.92 , respectively which are indicative of model's good fit. The ratio of $\chi^{2}$ to freedom degree was measured 2.24 which was less than 3 . Thus, it can be concluded that the produced model had sufficient and appropriate fit. As observed in Figure 2, factors of organizational structure and organizational culture have attained the most importance respectively among all 5 identified factors with the most significant regression coefficient on successful knowledge management. The next factors were IT infrastructure, strategy and leadership, and human resources.

\section{Conclusions}

Nowadays, knowledge management has strategic role in realization of business targets of the organization in addition to simplify its operational affairs, such that they are ought to codify strategic plan of KM in order to realize its role. This study aims to identify critical success factors of KM. A review on literature revealed the effective factors on successful implementation of KM and their significance was evaluated using factor analysis. Afterwards, conceptual model of these critical factors were

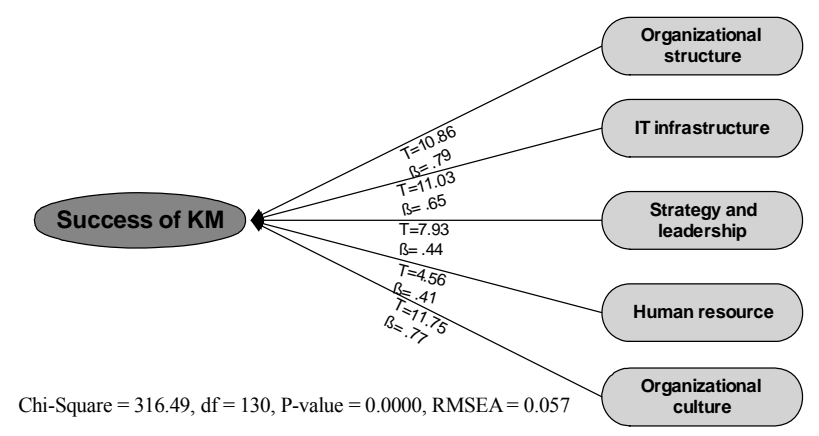

Figure 2. The second order CFA. developed within the organization under study. With respect to the proposed conceptual model, critical success factors of KM included aspects of organizational culture, organizational structure, strategy and leadership, IT infrastructure and human resources. Each of these features is composed of sub-criteria itself. Many of these criteria have been recognized in outspread researches as effective factors on successful KM. Comparing the research model with earlier studies shows that the recent model is much more complete than previous models; meanwhile it has been localized for the organization under study (Tehran Municipality, as a semi-governmental organization). Comparative study of the current results with the previous ones, indicates that models of Cherides et al. (2003), Simonch and Sinchler (2004), Holt (2007) [5], and Jalaldeen (2009) have also emphasized on the organizational culture in implementation of knowledge management. Furthermore, comparison with other proposed models such as Simonch and Sinchler (2004), Queen (2005), Holt et al. (2007) [5], and Jalaldeen (2009), reveals that they have all highlighted the effect of IT infrastructure in preparedness for implementation of KM but Cherides et al. (2003)., Amiden and Skyrme (1997) [17], Holt (2007) [5], Suriya and Hamid (2007) have not attained to such a result. For the third important success factor in implementation of KM considering the importance of leadership and strategy in various models including Simonch and Sinchler (2004), Queen (2005), Holt (2007) [5], and Jalaldeen (2009), they have insisted on its significance in proper implementation of KM and have offered results similar to the current research. The fourth important factor which has been obtained in the current research is the organizational structure. Holt (2007) [5] and Jalaldeen (2009), have emphasized on the importance of organizational structure in success or failure of implementing KM. Various authors such as Simonch and Sinchler (2004), Quin et al. (2007), Holt (2007) [5], and Cherides et al. (2003) have also verified that human resources is one of the main factors to implement $\mathrm{KM}$ within any organization. Generally speaking, it can be argued that the effect and relation between critical factors have often been noticed qualitative and intrinsically. However, this research, besides identifying the factors, has also adopted to study the extent of these effects in the framework of a comprehensive model. The practical results obtained from this research are summarized below:

- Organizational culture must be able to provide the required bases for sharing the knowledge during implementation of $\mathrm{KM}$ and encourage its creation and share focusing on the value of knowledge. The organizational culture must also prepare a trust context based on cooperation within the organization.

- Infrastructure of information technology and communications can be considered as one of the major en- 
ablers in constructing bases of IT which supports and coordinates KM. IT is one key enabler in executing $\mathrm{KM}$ since it is able to search quickly, access and recover information, support cooperation and relations among the members. Knowledge management should not be regarded the same as using IT systems, since KM has rather a broader concept which can employ IT as an enabler. For efficiency of KM it should be noted that IT must include simple technology, simple use, suitable for user needs and related to knowledge content.

- Knowledge management in an organization is directed to a large extent by its strategies while the source of these strategies is composed of principles and plans within the organization. Leadership has also a concept dependent on KM strategy and application of KM requires supports from senior management (in order to allocate adequate resources and time for KM models and plans). Indeed, it can be said that one essential principle to succeed in $\mathrm{KN}$ plans is to create constant strategic commitment to KM by senior managers of the organization. Leadership in the context of KM must be indicative of special characteristics which lead to knowledge management, some of these characteristics are: ability to create an environment for discussions, specialized dialogues about topics related to removal of obstacles of traditional structures which have been built by links of commandership inside the organization.

- Development of proper organizational infrastructures is one important aspect for implementation of $\mathrm{KM}$. Since, organizational structure is crucial in applying technology. Particularly speaking, the organizational structures must be flexible enough to increase distribution of knowledge and cooperation through boundaries of the traditional organization towards knowledge creativity. Successful implementation of the KM strategy depends on the flexible structure and removal of control and traditional systems. For example, horizontal organizations have authority for much flexibility against environments with quick and competitive changes of business.

Individuals are important factors in terms of social and cultural aspects of the organization. They build their organization so they are important for success. Those who are end users of system and technology, should be equipped to adequate skill and sufficiency, task expertise, attitude, positive though and culture to be accepted. Human resources are significant since any change or newly introduced technology will affect labor of the organization. Thus it is necessary to evaluate organizational culture and preparedness of individuals in acceptance of innovative and new technologies. Generally speaking, Individuals are regarded as personal contributors who have skills and knowledge roles, motivation and self-reaction, support, learning/social networks, dialogues, coordination and innovation. They create knowledge within the organization and a significant part of the organizational knowledge is saved in their minds.

\section{REFERENCES}

[1] N. N. Sunassee and D. A. Sewry, "An Investigation of Knowledge Management Implementation Strategies," Proceedings of the 2003 Annual Research Conference of the South African Institute of Computer Scientists and Information Technologists on Enablement through Technology, Tuinroete, 2003, pp. 24-36.

[2] T. H. Davenport and L. Prusak, "Working Knowledge: How Organizations Manage What they Know," Harvard Business School Press, 2000.

[3] B. Gupta and L. S. Iyer and J. E. Aronson, "Knowledge Management: Practices and Challenges, Industrial Management and Data Systems," Industrial Management \& Data Systems, Vol. 100, No. 1, 2000, pp. 17-21. doi:10.1108/02635570010273018

[4] I. Nonaka and H. Takeuchi, "The Knowledge-Creating Company: How Japanese Companies Create the Dynamics of Innovation," Oxford University Press, New York, 1995.

[5] D. T. Holt, S. E. Bartczak, S. W.Clark and M. R. Trent, "The Development of an Instrument to Assess Readiness for Knowledge Management," Knowledge Management Research \& Practice, Vol. 5, No. 2, 2007, pp. 75-92. doi:10.1057/palgrave.kmrp.8500132

[6] J. Rockart, "Chief Executives Define Their Own Information Needs," Harvard Business Review, Vol. 57, No. 2, 1979, pp. 81-92.

[7] A. Bruno and J. Leidecker, Identifying and Using Critical Success Factors," Long Range Planning, Vol. 17, No. 1, 1984, pp. 23-32. doi:10.1016/0024-6301(84)90163-8

[8] J. Pinto and D. Slevin, "Critical Factors in Successful Project Implementation," IEEE Transactions on Engineering Management, Vol. 34, No. 1, 1987, pp. 22-27.

[9] S. M. Allameh, S. M. Zare and S. M. R. Davoodi, "Examining the Impact of KM Enablers on Knowledge Management Processes," Procedia Computer Science, Vol. 3, 2011, pp. 1211-1223. doi:10.1016/j.procs.2010.12.196

[10] T. Davenport, D. De Long and M. Beers, "Successful Knowledge Management Projects," Sloan Management Review, Vol. 39, No. 2, 1998, pp. 43-57.

[11] P. Drucker, "Post-Capital Society," Harper \& Collins, New York, 1993.

[12] M. Demerest, "Undestand Management," Journal of Long Range Planning, Vol. 30, No. 3, 1997, pp. 374-384. doi:10.1016/S0024-6301(97)90250-8

[13] P. Gupara, "Why Knowledge Management Fails: How to Avoid the Common Pitfalls," 2000. www.melcum.com

[14] D. J. Flynn and E. A. Arce, "A Case Tool to Support Critical Success Factors Analysis in IT Planning and Requirements Determination," Information and Software 
Technology, Vol. 39, No. 5, 1997, pp. 311-321. doi:10.1016/S0950-5849(96)01150-0

[15] T. M. Somers and K. Nelson, "The Impact of Critical Success Factors across the Stages of Enterprise Resource Planning Implementation," Proceedings of the 34th Hawaii International Conference on Systems Sciences, Maui, 3-6 January 2001.

[16] M. Stankosky and B. Carolyn, "A System Approach to Engineering a Knowledge Management System," In: R. C. Barquin, A. Bennet and S. G. Remez, Eds., Knowledge Management: The Catalyst for Lectronic Government, Management Concepts, Vienna, 2001, p. 137.

[17] D. Skyrme and D. Amidon, "The Knowledge Agenda," Journal of Knowledge Management, Vol. 1, No. 1, 1997, pp. 27-37. doi:10.1108/13673279710800709

[18] C. W. Holsapple and K. D. Joshi, "An Investigation of Factors That Influence the Management of Knowledge in Organizations," Journal of Strategic Information Systems, Vol. 9, No. 2-3, 2000, pp. 235-61. doi:10.1016/S0963-8687(00)00046-9

[19] P. Chourides, D. Longbottom and W. Murphy, "Excellence in Knowledge Management: An Empirical Study to Identify Critical Factors and Performance Measures," Measuring Business Excellence, Vol. 7, No. 2, 2003, pp. 29-45. doi:10.1108/13683040310477977

[20] S.-H. Yu, Y.-G. Kim and M.-Y. Kim, "Linking Organizational Knowledge Management Drivers to Knowledge Management Performance: An Exploratory Study," 37th Hawaii International Conference on System Sciences, Big Island, 7-10 January 2002.

[21] Y. Wong, "Critical Success Factors for Implementing Knowledge Management in SME," Industrial Management \& Data Systems, Vol. 105, No. 3, 2005, pp. 261-279. doi:10.1108/02635570510590101

[22] S. C. Chong and Y. S. Choi, "Critical Factors in the Successful Implementation of Knowledge Management," 2005. www.tlainc.com

[23] K. Y. Wong and E. Aspinwall, “An Empirical Study of the Important Factors for Knowledge-Management Adoption in the SME Sector," Journal of Knowledge Management, Vol. 9, No. 3, 2005, pp. 64-82. doi:10.1108/13673270510602773

[24] Y. C. Hung, S. M. Huang, Q. Lin and M. L. Tsai, "Critical Factors in Adopting a Knowledge Management System for the Pharmaceutical Industry," Journal of Knowledge Management, Vol. 105, No. 2, 2005, pp. 164-168. doi:10.1108/02635570510583307

[25] P. Akhavan, M. Jafari and M. Fathian, "Critical Success Factors of Knowledge Management Systems: A MultiCase Analysis," European Business Review, Vol. 18, No. 2, 2006, pp. 97-113. doi:10.1108/09555340610651820

[26] Y.-J. Yeh, S.-Q. Lai and C.-T. Ho, "Knowledge Management Enablers: A Case Study," Industrial Management \& Data Systems, Vol. 106, No. 6, 2006, pp. 793-810. doi:10.1108/02635570610671489

[27] V. Anantatmula and S. Kanungo, "Modeling Enablers for Successful Km Implementation," Journal of Knowledge
Management, Vol. 14, No. 1, 2007, pp. 100-113. doi:10.1108/13673271011015598

[28] L. Huener, "Knowledge and Concept of Trust," Sage, London, 2001.

[29] S. P. Robbins, "Organizational Behavior: Concepts, Controversies, Applications," Prentice Hall, Upper Saddle River, 1996.

[30] F. J. Forcadell and F. Guadamillas, "A Case Study on the Implementation of a Knowledge Management Strategy Oriented to Innovation," Knowledge and Process Management, Vol. 9, No. 3, 2002, pp. 162-171. doi: $10.1002 / \mathrm{kpm} .143$

[31] R. Sanchez, "Creating Modular Platforms for Strategic Flexibility," Design Management Review, Vol. 15, No. 1, 2004, pp. 58-67. doi:10.1111/j.1948-7169.2004.tb00151.x

[32] F. Soliman and K. Spooner, "Strategies for Implementing Knowledge Management: Role of Human Resources Management," Journal of Knowledge Management, Vol. 4, No. 4, 2000, pp. 337-345. doi:10.1108/13673270010379894

[33] M. Santoro and A. K. Chakrabarti, "Firm Size and Technology Centrality in Industry-University Interactions," Research Policy, Vol. 31, No. 7, 2002, pp. 1163-1180. doi:10.1016/S0048-7333(01)00190-1

[34] A. Abelland and N. Oxbrow, "Competing with Knowledge," Library Association Publishing, London, 2001.

[35] F. Hasanali, "Critical Success Factors of Knowledge Management," 2002. www.infotoday.com

[36] S. Walczak, "Organizational Knowledge Management Structure," Learning Organization, Vol. 12, No. 4, 2005, pp. 330-339. doi:10.1108/09696470510599118

[37] H. Mintzberg, "Power in and Around Organizations," Prentice Hall, Upper Saddle River, 1983.

[38] T. Andersson and T. Westterlind, "Sharing Knowledge over Company Borders Managing Knowledge in Key Customer Relations at ABB Sweden," Master's Thesis, Linköpings University, Linköpings, 1999.

[39] M. Adenfelt and K. Lagerstro, "Enabling Knowledge Creation and Sharing in Transnational Projects," International Journal of Project Management, Vol. 24, No. 3, 2005, pp. 191-198. doi:10.1016/j.ijproman.2005.09.003

[40] H. Lee and B. Choi, "Knowledge Management Enablers, Processes, and Organizational Performance: An Integrative View and Empirical Examination," Journal of Management Information Systems, Vol. 20, No. 1, 2003, pp. 179-228.

[41] K. Ruikar, C. Anumba and P. Carrillo, "VERDICT-An E-Readiness Assessment Application for Construction Companies," Automation in Construction, Vol. 15, No. 1, 2006, 98-110. doi:10.1016/j.autcon.2005.02.009

[42] A. Brand, "Knowledge Management and Innovation at 3M," Journal of Knowledge Management, Vol. 2, No. 1, 1998, pp. 17-22. doi:10.1108/EUM0000000004605

[43] R. McDermott, "Why Information Technology Inspired But Cannot Deliver Knowledge Management," California Management Review, Vol. 41, No. 4, 1999, pp. 103-117. 
[44] S. Moffett, R. McAdam and S. Parkinson, "An Empirical Analysis of Knowledge Management Applications," Journal of Knowledge Management, Vol. 7, No. 3, 2003, pp. 6-26. doi:10.1108/13673270310485596

[45] Economic and Social For Western Asia, "Knowledge Management Methodology: An Empirical Approach in Core Sectors in Escwa Member Countries, Economic and Social For Western Asia," United Nations, New York, 2003.

[46] S. Zuboff, "In the Age of the Smart Machine," Heinemann, London, 1988.

[47] H. Scarborough, J. Swan and J. Preston, "Knowledge Management: A Literature Review," Institute of Personnel and Development, London, 1999.

[48] R. Ruggles, "The State of the Notion: Knowledge Management in Practice," California Management Review, Vol. 40, No. 3, 1998, pp. 80-89.

[49] D. Shenk, "Data Smog," Harper \& Collins, New York, 1997.

[50] J. Tian, Y. N. Yoshiteru and P. W. Andrzej, "Knowledge Management and Knowledge Creation in Academia: A Study Based on Surveys in a Japanese Research University," Journal of Knowledge Management, Vol. 13, No. 2, 2009, pp. 76-92. doi:10.1108/13673270910942718

[51] M. Alavi and D. E. Leidner, "Review: Knowledge Management and Knowledge Management Systems: Conceptual Foundations and Research Issues," MIS Quarterly, Vol. 25, No. 1, 2001, pp. 107-136.

[52] K. Mathi, "Key Success Factors for Knowledge Management," Master's Thesis, University of Applied Sciences/Fh Kempten, Kempten, 2004.

[53] F. Hair, E. R. Anderson, L. R. Tatham and C. W. Black, "Multivariate Data Analysis," 5th Edition, Prentice Hall, Upper Saddle River, 1998.
[54] G. A. Churchil Jr., "Aparadigm for Developing Better Measures of Marketing Constructs," Journal of Marketing Research, Vol. 16, No. 1, 1979, pp. 64-73. doi: $10.2307 / 3150876$

[55] R. Jalaldeen, et al., "Organizational Readiness and Its Contributing Factors to Adopt KM Processes: A Conceptual Model," Communications of the IBIMA, Vol. 8, No. 17, 2009, pp. 128-136.

[56] K. Mohammadi, A. Khanlari and B. Sohrabi, "Organizational Readiness Assessment for Knowledge Management," International Journal of Knowledge Management, Vol. 5, No. 1, 2009, pp. 29-45.

[57] C. Siemieniuch and M. Sinclair, "A Frame-Work for Organizational Readiness for Knowledge Management," International Journal of Operations \& Production Management, Vol. 24, No. 1, 2004, pp. 79-98. doi:10.1108/01443570410511004

[58] T. Quin and Y. Tan, "Knowledge Management Readiness in Organisation: A Case of Public Sector in Malaysia," International Conference on Knowledge, 7-9 July 2005.

[59] W. A. Taylor and G. H. Wright, "Organizational Readiness for Successful Knowledge Sharing: Challenges for Public Sector Managers," Information Resources Management Journal, Vol. 17, No. 2, 2004, pp. 22-37.

[60] S. Gaffoor, "Assessing Readiness for the Implementation of Knowledge Management in Local Governments: The case of Stellenbosch Municipality," Master's Thesis, Commerce at Stellenbosch University, Stellenbosch, 2008.

[61] K. R. Youshanloui, F. Daneshgar, N. Sarabi, H. R. Youshanlouei and M. M. Mood, "An Intelligent Model to Asses Organizational Maturity for Implementation of Knowledge Management," 12th European Conference on Knowledge Management, Passau, 1-2 September 2011. 